\title{
"I Internalize Islamic Values": Bachelor Nursing Students' Perception and Experience of Professional Identity in Indonesia
}

\author{
Wulan Noviani*, Lisa Musharyanti, Rangga Putera Anugerah Pratama \\ School of Nursing, Faculty of Medicine and Health Sciences, Universitas Muhammadiyah Yogyakarta, Yogyakarta, Indonesia
}

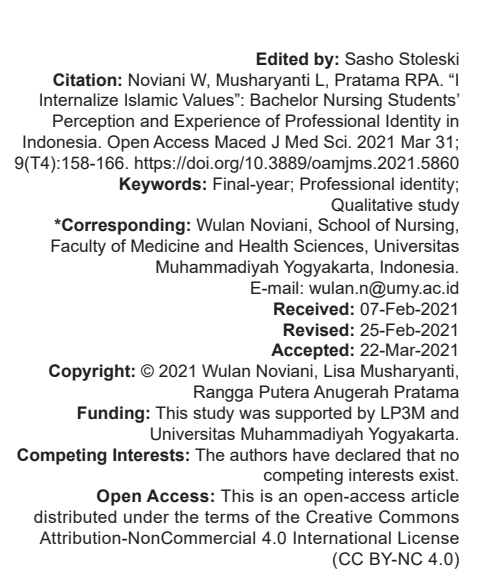

\section{Introduction}

Professional identity is a crucial aspect in nursing that shapes professional nurses' characters and ensures the longevity of nursing career and job satisfaction [1]. Besides, professional identity is vital in the transition and decision-making for the nursing student in selecting a future nursing career [2]. However, the professional identity concept is not set out clearly in the literature [2], [3]. In terms of professional identity, it has been associated with nursing professionalism [3], [4], professional self-concept [5], [6], [7], and professional socialization results [8], [9], [10]. Recently, Fitzgerald clarified professional identity, including attributes, skills and roles, knowledge values and ethics, individual identity, group identity, and the influential care context [11]. Professional identity comes from self-perception of "who I am," "what I do," and "where I do it as a professional nurse" [1], [12]. Moreover, professional identity is a personal perception of the nursing profession formed by values, beliefs, motivation, and personal experience in working life [13]. Therefore, professional identity is undoubted to improve the nursing profession constructed by strong perception [1], [2], [3], [10], [12], [13].
Professional identity is a brand of occupational identity constructed by self-image [2] and public image [5], [6]. Professional identity has to be perceived by the nursing students who have not yet established their own identity through brand nursing identity, public image, and professional working [2]. Apparently, professional identity has developed significantly in Asian countries. In Iranian nursing, professional identity has been highlighted by social-cultural structure, values, and beliefs in governing health systems [5]. Furthermore, nursing students' and nurse's professional identity in China has influenced multidimensional factors, such as social, personal, family, and institutional [14]. However, there is urgency in improving nursing image to achieve professional status through identity as professional nurses in Indonesia [15], [16], [17], China [14], [18], Iran [5], [19], [20], and Saudi Arabia [21], [22]. Besides that, a nursing image could be enhanced by the roles of a nursing education institution that instill professional values suitable for the character identity of nurses [23], [24], devise strategies to attract males to choose a career in nursing, and enhance retention into the nursing profession after graduation [25]. However, nursing education should revise the educational system not to follow the Western nursing curricula and connect it with nursing students' cultural context and gender 
roles [25]. Thus, nursing education institutions could create career opportunities and focus not only on professional competence but also on promoting strong professional identity [26].

Florence Nightingale is the founder of modern nursing who has a strong identity as a professional nurse. She is known as Lady with Lamps, who has many roles, including providing care during war, nurse educator, statistician, and clinical epidemiologist [27]. She succeeded in enhancing the nursing profession status through her high moral character from a disreputable and immoral vocation into the honest and ethical profession [28]. Meanwhile, in Muslim nursing history, there has been found a first Muslim nurse who lived in the Prophet Muhammad era, namely Rufaida al Asalmiya [28], [29]. Rufaida showed that nursing is a noble career for Muslim women suitable with Islamic tradition [28]. She was recognized as a great role model in nursing with many roles, including care provider, nurse educator, nurse leader, and founder of first nursing school and clinics [29], [30]. She also was acknowledged as the first Muslim woman who reflected gender equity while working with males in wars. It provides the golden chance for developing the identity of Muslim nurses into the nursing profession [30].

Islamic professional nurses are School of Nursing's expected outcomes, Universitas Muhammadiyah Yogyakarta (UMY), where nursing students display the identity as Islamic nurses suitable with organizational cultures. It has been accredited $A$ since 2015 and maintained its accreditation in 2019 for academic and professional programs. Studentcentered learning was used based on the Association of Indonesian Nurses Education Center (AINEC) [31] and integrated Islamic revealed knowledge (IRK) into whole nursing curricula. Indonesian Bachelor nursing program comprises two stages, namely, academic program (e.g., a classroom, laboratory, and pre-clinical for eight semesters) and professional programs (e.g., in community and clinical education for two semesters) [32]. Thus, final-year student nurses' perception and experience of professional identity are necessary to explore.

\section{Methods}

This study was a descriptive qualitative study to gain insight into a professional identity final-year bachelor nursing student [33] with a drawing exercise to gain images of a professional nurse [2]. The qualitative descriptive design was considered the most suitable for an in-depth examination of the participant's experience [34].

The participants were 13 final-year student nurses who undertook a professional program from four academic hospitals of UMY in Indonesia. The convenience sampling technique and a semi-structured interview guideline were used in this study. Each group consisted of three to four students and the saturation data was achieved in four group interviews. The main goal of each group interview was to explore students experience and their perception about professional identity. WhatsApp video call and digital recorder were used for data collection within 45-60 min on August 2020. The interview questions included defining the meaning of Islamic professional identity, their challenges to develop professional identity, and how they tackle it. The participant then drew about Islamic professional nurses through critical reflection based on their perception and experience in clinical education as well as a visual representation of their identity. Student nurses also have discussed their images, including nurse's roles, characters, and Islamic nurses' appearances. Drawing or artwork provides a way to communicate the student nurses' knowledge and understanding related to the meaning of professional identity [2], [35]. After completing of each interview, the researchers listened to the recorder for general and transcribed independently in Microsoft Word 2013. This has been done the transcription for all interviews within $24 \mathrm{~h}$ of the interviews.

The data were thematic analysis used the methods of Colaizzi analysis and NVivo 12 plus software. Seven methods of Colaizzi analysis were: (1) Familiarization of data (read and re-read transcripts, and listened back of the recorded interviews); (2) identification of significant statement ("...our identity as a sign that we as Muslim nurses by giving Islamic values for patients); (3) formulation of meanings (student perceive as Muslim nurse); (4) clusterization of the themes (total 13 cluster, with five themes); (5) development of exhaustive description (Islamic nurse is my identity); 6) fundamental structure (Islamic professional identity); and (7) verification of fundamental structure (all participants provide checking the transcribed and feedback) [36], [37].

This study has ensured the ensuring the rigor in qualitative nursing that proposed by Carnevale's four criteria, including credibility, conformability, saturation, and transferability [38]. In this study, the credibility was maintained by long-term engagement with participants until 3 times interactions, discussion with experts (reviewed the interview transcripts, images, and field notes), and write reflective journals for bracketing the researcher assumptions. An attempt was made for conformability include sent a copy of the transcript for all participants for member checking, follow-up interview and audit trails. For saturation included flexible sample size (recruit 13 participants from four academic hospitals, both gender) and saturation data were achieved by four group interviews. The transferability was used a comprehensive and full description of the research context to improve generalization and 
application of finding in other situation with similar circumstances. The research ethics board approved this study with the number 1340/KEP-UNISA/VIII/2020. This study was ensured participant's confidentiality and maintains students' participation will not influence academic scores.

\section{Results}

The sample included a total number of 13 final year nursing students. Out of 13 participants, ten were females, and three were males. The average age was 22 years old. Thirteen images were collected as part of the study. Table 1 themes and sub-themes of the study findings.

Table 1: Themes and subthemes of the findings

\begin{tabular}{ll}
\hline Themes & Sub-themes \\
\hline Islamic nurse is my identity & - Sign as a Muslim nurse \\
& - Nursing image \\
- Covering self-aurat (body) & - Maintaining patient's aurat \\
I follow Islamic sharia & - Prioritizing gender \\
& - Belief in God \\
& - Sincerity \\
I internalize Islamic values & - Paring \\
& - Beviding Islamic nursing care \\
I practice professional roles & - Being a communicator \\
& - Nursing ethics \\
I obey professional regulation & Professional competence \\
\hline
\end{tabular}

The participants drew the professional image that showed the Islamic nurses' identity, and they discussed in the group interviews. Most of the participant images contained gender identity, roles of nurses, and Islamic professional nurse attributes. The researchers analyzed the images using thematic analysis and a modified version of Rose's (2001) critical visual methodology framework, proposed by Guillemin (2004). It considered the participants, the researcher, and the images themselves [2], [39]. The researchers were independently assigned to the images and the text. The analysis has compared the images with the text that could enhance the validity of the research data. These images aim to strengthen the perception of students related to their professional identity and support the interview data. Analysis followed the Guillemin questions list, including the production of images, images, and the relationships between the image and audience [39]. The participants illustrate the images below.

The image illustrates the meaning of female nurse care in Indonesia. The participant drew and wrote the abbreviation of nurses in the Indonesian language, including care, empathy, religious, active, broad insight, expert, and competent. The image of female nurses with Islamic identity, include wearing long uniforms, the veil covering the head into the chest, and identity name. The image also showed a smiling face indicating that the female nurses are ready to be taking care of the patient. There are several tools related to nurses' jobs, including a stethoscope, injection, and medication prescribed by the physician. The participant also drew a hat with a plus like the Indonesian Red Cross, which focuses on care and humanity (Figure 1).

The image illustrates a female Ners UMY with various characters. The participant drew and wrote the nurses' characters in the Indonesian language. Furthermore, a participant wrote characters, include professional, good attitude/akhlak, critical thinking, respect, easy to remind, skillful, compassionate, spreading benefits, energic, positive thinking, and having self-control. Then, UMY nurses' characters include communicative, friendly, providing service, tolerant, empathy, caring, spreading greetings, responsible, praying for the patient, ensuring patient safety, spreading goodness, sincere, active listener, and useful in time management. The image reflects the female students wearing UMY Ners uniform with a headscarf and identity card (Figure 2).

The image illustrates the roles of a professional nurse. The participant drew and wrote various nurses' roles, such as caregiver, advocate, educator, collaborator, and consultant. The image of a male nurse is such as wearing a stethoscope. The plus sign means the nurses' job is related to giving medication, administration, and blood. The heart sign means the caring behavior of a professional nurse (Figure 3 ).

The image illustrates a male Ners UMY with a white uniform and identity card. The participant described the characters and identity of the male nurse. It includes wearing neat and syar'i clothes, strong, caring, right in time management, being an active listener, and self-confidence. Then, nurses are being friendly (with the patient, family, and nurses), tolerant, adaptable, smart, skillful, proud with their profession, and can be a leader (Figure 4).

\section{Theme 1. Islamic nurse is my identity}

Based on the data, it was evident that participants perceived that Islamic nurses and UMY have embedded in their identity. As a result, all participants shared and discussed deeply based on the nursing profession's image, and aware that they are Muslim nurses. There were two sub-themes identified: Sign as a Muslim nurse and nursing image.

\section{Sign as a Muslim nurse}

The majority of participants stated and reflected their identity as Muslim nurse. Participants explained that personal identity was attached to institutional identity and Islamic religion. It described in the following statements:

"...my identity means that if people see me as Islamic nurses, so that is the identity attached to me as UMY nurses, people already have a 
picture of UMY, and I can apply it in my daily lives. The identity is attached to me so without explaining people they already know that UMY identity..." (FG1, P1).

"...our identity as a sign that we as Muslim nurses by giving Islamic values for patients." (FG2, P5).

\section{Nursing image}

The participants explained that patients preferred to taking care of themselves as UMY nursing students. Student's nurses have undertaken the professional program, and they have experience in clinical practice for more than 7 months. Then, they stated that the nursing services assessed by patients had a positive nursing image for them. The views are explained in the following statements:

"...I prefer to be treated by you who wears UMY white clothes because you can make painstaking slowly when giving the injection said patient $A$..." (FG1, P2).

"...patients often compare with other practitioners; they said that UMY students are more friendly and often pray for the patients. Patients also often ask to be treated later, sis will take care of me..."(FG3, P7).

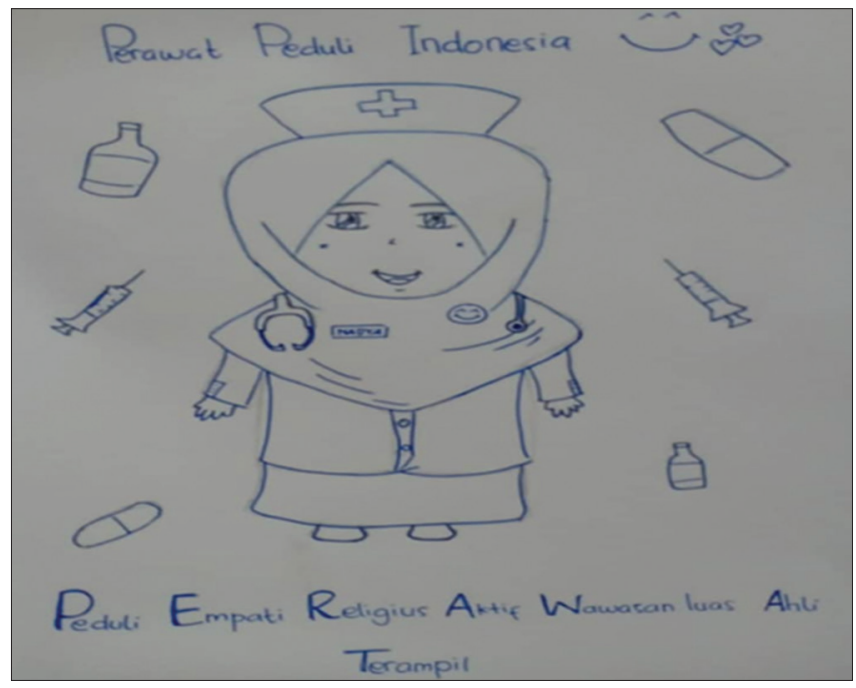

Figure 1: Image of female Islamic nurse

\section{Theme 2. I follow Islamic sharia}

Based on the data, it was evident that nursing students follow Islamic shari'a. There were three subthemes identified, namely: Covering self-aurat/ body, maintaining the patient's aurat, and prioritizing gender.

\section{Covering self-aurat}

The participants stated that they covered their self-aurat as a way to show they are Islamic nurses. Here are the following statements:
"Showing a nurse who is Islamic...by closing the aurat..." (FG1, P3).

"...women wear a headscarf and dress tidy while men are neat and polite and there is a characteristic of Islamic nurses especially women hijab covering the chest and long clothes..." (FG4, P11).

\section{Maintaining patient's aurat}

The participants mentioned keeping the patient's aurat and ensuring patient privacy when conducting the nursing intervention. Here are the following statements of the participants:

"I pay more attention to the patient's aurat, for example, when bathing the patient so I covered partly not to make it all exposed, so some restrictions that are closed, and also I pay attention to their privacy." (FG3, P7).

"...when carrying out nursing care for ill patients, I also maintain the patient's aurat..." (FG4, P12).

\section{Prioritizing gender}

The participants expressed providing nursing care based on patient gender. They also asked permission before the nursing intervention. Here are the following statements of participants:

"...when conducting nursing care to patients, for example, I manage to respect the male or female patients and the care of patients when I did the intervention to the opposite gender and also respect the rights of patients to choose..." (FG3, P8).

"...prioritizing care based on the patient's gender, so if you want to install a male patient catheter as much as possible, a nurse will install a male patient. However, if there is no male nurse, I can do it but with the consent of the patient." (FG2, P4).

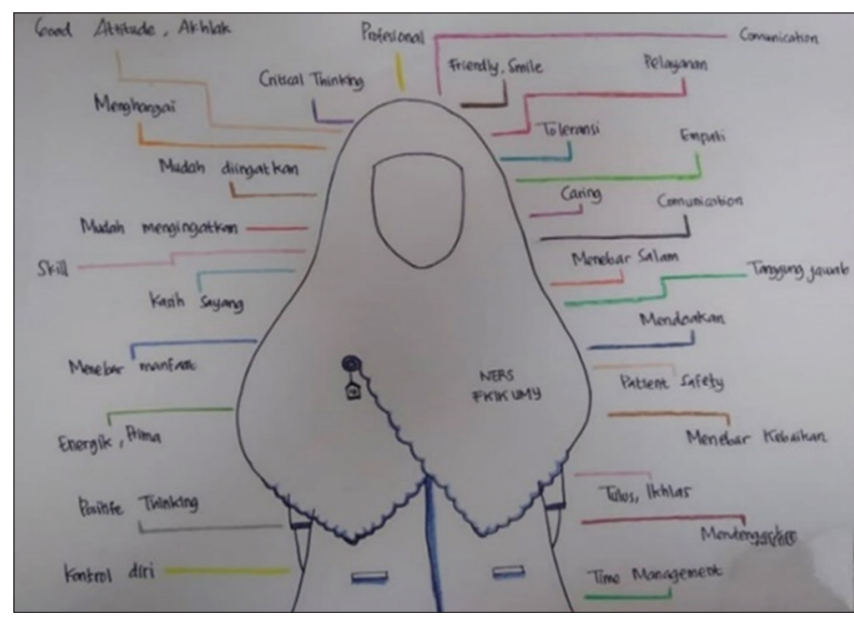

Figure 2: Image of female Islamic nurse 


\section{Theme 3. I internalize Islamic values}

Based on the data, it was evident that nursing students internalize Islamic values. There were three sub-themes identified, such as: Belief in God, sincerity, and caring.

\section{Belief in god}

All participants stated they had a surrender in God (Allah SWT) who guides and manages their way of life. Here are the following statements of the participants:

"...I assuming that what I do is lillahi'taala to help patients..." (FG1, P3).

"I believe in the way God has given me, and I believe that is the best for me..." (FG3, P10).

\section{Sincerity}

Participants explained that they acknowledged doing nurses' jobs with sincerity. Here are the following statements of the participants:

"...applying friendly service and care to patients regardless of the patient's background and serving sincerely... (FG3, P8).

"...taking care of patients sincerely without feeling heavy..." (FG4, P13).

\section{Caring}

The participants stated that caring is shown by admitting that the patient was like her mom, doing the best for the patient, and being aware that nursing's main task is caring. The following statements of participants: "...in my mind when I took care of the patient, I imagine that I was taking care of my mom, so I did my best for her..." (FG1, P3)

"...try my best to remain empathetic to the patient or patient's family without considering anything else..." (FG2, P5)

"...based on shari'a and obligations as health workers to be willing to carry out our duties in clinics or communities, the main task is more to caring so that it is better spiritual, social, and biopsychological." (FG3, P9).

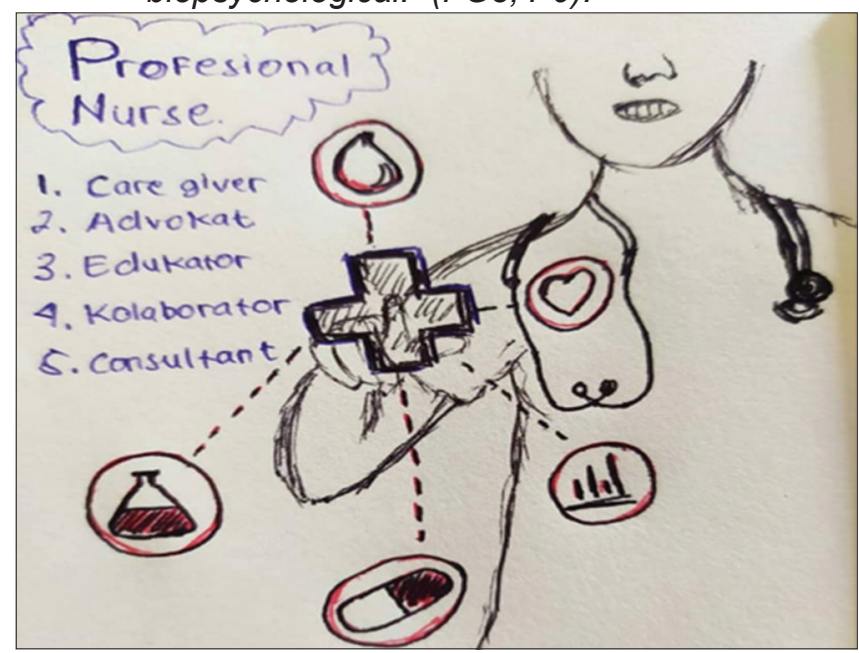

Figure 3: Image of male Islamic nurse

\section{Theme 4. I practice professional roles}

Based on the data, it was evident that nursing students internalized the Islamic values. There were three sub-themes identified: Providing Islamic nursing care, being an educator, and being a communicator.

\section{Providing Islamic nursing care}

The participants also conveyed that they provided spiritual care by reminding patients to pray, assisting them to pray, reminding them of dhikr, and praying for patient health. Here are the following statements of the participants:

"I assisted patients in fulfilling spiritual needs while in the hospital, for example, reminding patients to pray, do dhikr, reminding the patient to be patient, and pray for the patient's recovery..." (FG2, P4).

"...I have applied Islamic nursing care for patients, including bio-psychosociocultural and spiritual. So I have provided prayed for the patient saying "syafakallah or syafakillah" and assisting them to pray during their sickness..." (FG4, P13).

\section{Being an educator}

The participants explained that they became an educator for patients and families related to nursing information, taught to purify and da'wah to provide spiritual care. Here are the following statements of the participants:

"...l taught the patient how to do taharah (purify) and assistelld them to pray with a urinary catheter in the bed..." (FG2, P8).

“...da'wah at the same time through reminding the patient of Allah, dhikr and being patience. I also taught them when there are encountered problems in worshipping process during their sickness..." (FG4, P12).

\section{Being a communicator}

The participants also stated that they learned to be good communicators in clinical education, although they spoke different languages with the patient. Here are the following statements of the participants:

"Even though I do not speak Javanese when treating patients, it turned out that this was not a barrier to communicate. When I provided information using the Indonesian language, they understood what I said..." (FG1, P1)

"...during my clinical education, my communication skill improved. I always explain all of the things well to prevent misunderstanding with patients, family, colleagues, and other health workers." (FG2, P6). 


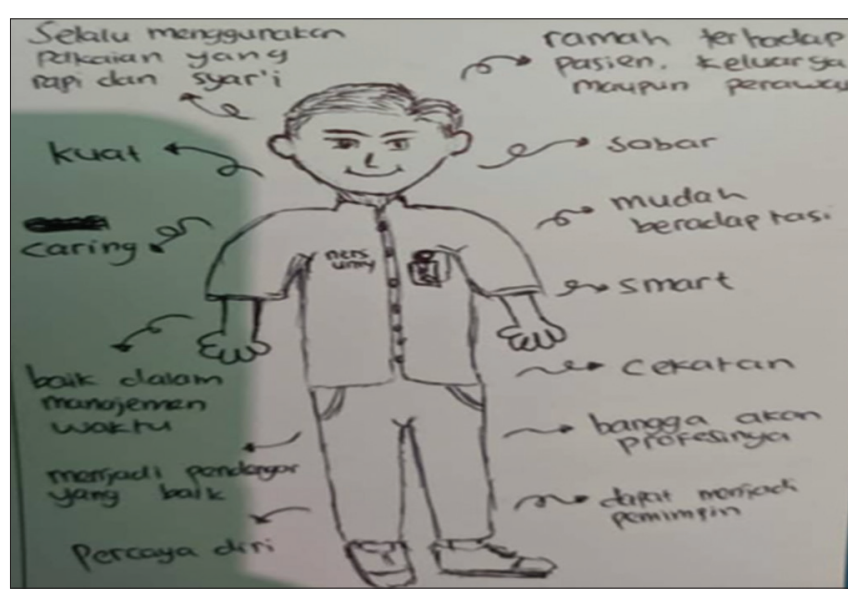

Figure 4: Image of male Islamic nurse

\section{Theme 5. I obey professional regulation}

Based on the data, it was evident that nursing students obey professional regulation. There were two sub-themes identified, namely: Nursing ethics and professional competence.

\section{Nursing ethics}

The participants stated that they apply nursing codes of ethics and maintain patient rights in their nursing intervention. Here are the following statements of the participants:

“...as Islamic nurses, I obey the nurses' ethic codes and pay more attention to nursing ethics." (FG1, P3).

"...l ensure the patient's privacy when taking care of them through closing the door and keep the patient's right..." (FG3, P10).

\section{Professional competence}

The participants explained that authority and competence were essential to do nursing care. They were also aware of improving their competency comprehensively, such as knowledge, skill, and right attitude. Here are the following statements of the participants:

\footnotetext{
"doing nursing care under the responsibilities and authorities possessed and competencies so that I see and pay more attention when taking action to patients. I also apply my professionalism according to the competencies..." (FG2, P6).

"not only knowledge and skill but also a good attitude to become an Islamic professional nurse. I try to develop my competency in clinical practice..." (FG4, P12).
}

\section{Discussion}

The study was a descriptive qualitative study to analyze the perception and experience of final-year bachelor nursing students on Indonesia's professional identity. Findings found reflecting Islamic values suitable with the goals of UMY institution to form the identity as Islamic professional nurses and excellence. Nursing is a form of professional service. It is an integral part of health service based on nursing science and art, aiming to provide care to individuals, families, and communities, whether they are healthy or sick [40]. Evidence revealed that Muslim nurses struggle with recognizing social status and professional identity [30]. Then, a positive professional identity can contribute to personal, social, and professional fulfillment [18]. In fact, the reconstruction of nurses' professional identity can improve nurses' professional image by emphasizing nurses' roles and positive characters such as accountability, responsiveness, ethical, communicative, caring, and expertise [5].

Findings revealed that students have awareness about their Islamic identity that brings to their identity. Students have instilled the Islamic ideology from the Quran and Sunnah of Prophet Muhammad during their education in UMY. The Islamic curriculum has implemented into the teaching and learning process in the Bachelor nursing education, both academic and profession stage for 5 years, and this process called professional socialization. It brings Islamic values to internalize into their behavior in daily life and shape a strong professional identity as the result of professional socialization. Islamic ideology refers to reflective analysis about what we think and know of our world and ourselves. It attempts to understand an Islamic ideology rooted in fair truth [41]. Islamic belief is based on the Qur'an, the Holy Book of Muslims, and the Sunna, which refers to the Prophet's life and practices [30]. In this study, students follow the Islamic sharia when taking care of the patients through maintaining self-aurat, patient's aurat, and prioritizing gender. Islamic sharia (human rights and human security) strives to obtain the benefits for the individual and community to protect them from harm not only for Muslim society but also for non-Muslims. Thus, a person in Islam is entitled to respect regardless of race and religious practices [30]. Health-care providers should then consider modesty during the examination, predominantly Muslim females, by asking permission before uncovering their body parts [42], [44]. Muslim females may prefer to be examined by female health providers; however, this might not always be feasible. In some cases, a male nurse examines Muslim female patients [44]. 
Islamic values are internalized by students through belief in God, sincerity, and caring. Evidence found that Islamic values have influenced the Indonesian undergraduate nursing students to provide nursing care, which is the way to getting closer to God and getting a reward in Hereafter [32], [43]. Muslim recognizes the five pillars of Islam and practices them, including: (1) Declaration of faith, (2) formal prayer/salat, (3) tithing/zakat, (4) fasting/saum, and (5) pilgrimage/hajj [30], [41]. Furthermore, the true essence of Islam is submission and adherence to Allah's commandments without objection. By obeying Allah, the Muslims would be in harmony with the universe in their lives; they abide by Allah's commands for all of this world [30]. Islamic literature found that caring is rooted in theological Islam, which is expected to be a result of having and showing love for Allah [43]. Caring principles are based on divine revelation and the Prophet's habits (sunnah) [30]. Besides, caring is the essence of nursing and fundamental in nursing practice [18]. Caring means the willingness to be responsible, compassionate, and concerned with the encouragement and commitment to behave in the right way of perfection [44], [46]. Furthermore, caring in the Islamic philosophy acknowledged that values, beliefs, and culture influence transcultural nursing quality [44], [45]. It highlights that Muslim nurses should provide meaningful care by paying attention to the patient's cultural, spiritual, and religious practices [44]. It is supported by evidence of Indonesian nursing students perceiving caring as the most important professional values [32].

In the current study, students perceived many professional roles by providing Islamic care, being an educator, and communicating with the patient and their family. Professional roles became the part of professional identity that was perceived by Indonesian nursing students. It is supported by a review Rasmussen et al. that have identified three major components of professional identity in nursing included the self (who I am), the role (what I do), and the context (where I do) [1]. Findings found that students learn to provide spiritual care by reminding patients' to pray, dhikr, and educate how purifying (taharah). They also offer to pray for their recovery and remind to be patient. It should be noticed that nurses should know that the primary source of hope comes from a Muslim's belief and faith in Allah. It is emphasized that the cure is in Allah's hand, so nurses could bring hope by reminding the patient to Allah and praying [44]. Besides, Muslim nurses perceived their roles as spiritual practice providers, their patients as spiritual beings, and caring to serve the physical and spiritual needs [48].

Furthermore, Almukhaini et al. emphasize the importance of helping Muslim patients meet their spiritual and ideological needs by respecting their religious practices. Muslim nurses need to understand that Muslim patients perceive suffering, illness as life's parts, and the suffering may be the way by which Allah is testing one's beliefs [44]. Watson asserts that nurses should learn and support their values and beliefs and integrate into holistic nursing care [47]. While the Qur'an holistically views human life, meaning a harmony between spirit (Rouh), mind $(A g h l)$, soul (Nafs), intellect (Aghel), physical (Badan), and emotional (Atefah) [30]. Findings revealed that students provide holistic nursing care to fulfill the patient's need, involving biological, psychological, social, cultural, and spiritual aspects. Students also perceived the role of being a communicator for the patient and their family. Nurses could improve their communication with Muslim patients using hope and faith-provoking phrase, such as (1) inshallah/if God willing; (2) alhamdu-li-llah/ thanks God; (3) tahour in shaa Allah/ purified InsyaAllah; and (4) astagfer Allah/ asking forgiveness-to Allah [44]. The study finding was relevant to the School of Nursing UMY, and AINEC graduates profile, including care provider, communicator, educator and health promoter, leader, manager, and researcher [31].

Students follow professional conduct in practice, including nursing ethics and professional competence. They have a high commitment to obey the regulation in nursing practice. Nursing students UMY perceived that Indonesian nurses' ethics code is behavior guidance to provide nursing care [49]. Besides, codes of ethics are legal and fundamental guidance in professional nursing practice [50]. Indonesian nurses' codes of ethics stated that providing nursing care to fulfill patient needs is the primary responsibility of Indonesian nurses [32]. A previous study revealed a significant relationship between nurses' professional self-concept with a commitment to professional ethics that resulted in Iranian nurses' better performance [51]. Findings revealed that students have culturally competent to provide spiritual care and show their competence to fulfill patient needs. A study supported that European undergraduate nursing students held broad insight into spiritual care, and they perceived to be competent in the delivery of spiritual care, especially in the humanistic aspect [52].

Qualitative data showed a surprising phenomenon that students' images were reflected as Islamic nurses and brought UMY institutions into their identity. Strong professional identity resulted in a sense of belonging, self-confidence, selfesteem, self-image, public recognition, professional commitment [10], [53], [54], improve job satisfaction, and nurses' retention [2], [3], [18]. Besides, as Muslim culture, Islam has practiced by actualizing Islamic five pillars and other religious customs [42]. Findings revealed that nursing students bring Islamic culture into their practice, and the images of the nursing profession have drawn through Islamic appearances that follow Islamic guidance, nurses' roles, and Islamic 
nurses' characters. Findings also showed that students' have a strong professional identity as Islamic nurses that instills Islamic ideology into student's behavior and practices. Furthermore, findings revealed the professional identity perceived and experienced by final-year bachelor nursing students in Indonesia. Findings may help capture the student nurses' identity in Indonesia and provide recommendations that could enhance a positive nursing image.

\section{Conclusion}

The descriptive qualitative study sought to discover the essential meaning of final-year bachelor nursing students' professional identity in Indonesia. Findings could not be generalized to the whole population. This paper has concentrated on describing the students' insight and experience about their professional identity influenced by the collective identity, including Islamic religion, institutional identity, and the nursing profession. Professional identity has been attached to their identity as an Islamic nurse. These findings can contribute to curriculum development in the Islamic Bachelor nursing program that focuses on strengthening professional identity that resulted in a sense of belonging and nursing career choice.

\section{References}

1. Rasmussen P, Henderson A, Andrew N, Conroy T. Factors influencing registered nurses' perceptions of their professional identity: An integrative literature review. J Contin Educ Nurs. 2018;49(5):225-32. https://doi. org/10.3928/00220124-20180417-08

PMid:29701865

2. Browne C, Wall P, Batt S, Bennett R. Understanding perceptions of nursing professional identity in students entering an Australian undergraduate nursing degree. Nurse Educ Pract. 2018;32:906. https://doi.org/10.1016/j.nepr.2018.07.006 PMid:30098517

3. Johnson M, Cowin LS, Wilson I, Young H. Professional identity and nursing: Contemporary theoretical developments and future research challenges. Int Nurs Rev. 2012;59(4):562-9. https:// doi.org/10.1111/j.1466-7657.2012.01013.x PMid:23134142

4. Baker S. Outcomes and competencies for graduates of practical/Vocational, Diploma, associate degree, baccalaureate, master's, practice doctorate, and research doctorate programs in nursingdeveloped by the national league for nursing; New York: National league for nursing, 2010; 96 pages, \$29.95 (NLN members), \$34.95 (nonmembers)(soft cover). Nurs Educ Perspect 2011;32(3):201.

5. Yazdannik A, Yekta ZP, Soltani A. Nursing professional identity: An infant or one with Alzheimer. Iran J Nurs Midwifery Res

\section{2;17(2 Suppl1):S178-86}

PMid:23833602

6. ten Hoeve $Y$, Jansen $G$, Roodbol P. The nursing profession: Public image, self-concept and professional identity. A discussion paper. J Adv Nurs. 2014;70(2):295-309. https://doi. org/10.1111/jan.12177 PMid:23711235

7. Porter J, Wilton A. Professional identity of allied health staff. J Allied Health. 2019;48(1):11-7.

PMid:30826825

8. Lai PK, Lim PH. Concept of professional socialization in nursing. Int Sci Med Educ. 2012;6(1):5-31.

9. Dinmohammadi M, Peyrovi H, Mehrdad N. Concept Analysis of Professional Socialization in Nursing. Paper Presented at the Nursing Forum; 2013. https://doi.org/10.1111/nuf.12006

10. Zarshenas L, Sharif F, Molazem Z, Khayyer M, Zare N, Ebadi A. Professional socialization in nursing: A qualitative content analysis. Iran J Nurs Midwifery Res. 2014;19(4):432-8.

PMid:25183987

11. Fitzgerald A. Professional Identity: A Concept Analysis. Paper Presented at the Nursing Forum; 2020.

12. Frechette J, Bitzas V, Kilpatrick K, Aubry M, Lavoie-Tremblay M. A hermeneutic-phenomenological study of paediatric intensive care unit nurses' professional identity following hospital redesign: Lessons learned for managers. J Nurs Manag. 2020;28(4):87280. https://doi.org/10.1111/jonm.13012 PMid:32219900

13. Terry J. In the middle: A qualitative study of talk about mental health nursing roles and work. Int $\mathrm{J}$ Ment Health Nurs. 2020;29(3):414-26. https://doi.org/10.1111/inm.12676 PMid:31799780

14. Mao A, Lu SE, Lin Y, He M. A scoping review on the influencing factors and development process of professional identity among nursing students and nurses. J Prof Nurs. 2020;2020:1-18. https://doi.org/10.1016/j.profnurs.2020.04.018

15. Shields L, Hartati LE. Nursing and health care in Indonesia. $J$ Adv Nurs. 2003;44(2):209-16.

PMid: 14521687

16. Sommers CL, Tarihoran DE, Sembel S, Tzeng HM. Perceived images and expected roles of Indonesian nurses. Nurs Open. 2018;5(4):501-6. https://doi.org/10.1002/nop2.156 PMid:30338095

17. Gunawan J, Aungsuroch Y, Sukarna A, Efendi F. The image of nursing as perceived by nurses: A phenomenological study. Nurs Midwifery Stud. 2018;7(4):180-5. https://doi.org/10.4103/ nms.nms_24_18

18. Guo YJ, Yang L, Ji HX, Zhao Q. Caring characters and professional identity among graduate nursing students in China a cross sectional study. Nurs Educ Today. 2018;65:150-5. https://doi.org/10.1016/j.nedt.2018.02.039 PMid:29579567

19. Nasrabadi AN, Emami A. Perceptions of nursing practice in Iran. Nurs Outlook. 2006;54(6):320-7. https://doi.org/10.1016/j. outlook.2006.06.001

PMid: 17142150

20. Nasrabadi AN, Lipson JG, Emami A. Professional nursing in Iran: An overview of its historical and sociocultural framework. J Prof Nurs. 2004;20(6):396-402. https://doi.org/10.1016/j. profnurs.2004.08.004

PMid:15599874

21. Lamadah SM, Sayed HY. Challenges facing nursing profession in Saudi Arabia. J Biol Agric Healthc. 2014;4(7):20-5

22. Miller-Rosser K, Chapman $\mathrm{Y}$, Francis K. Historical, cultural, and contemporary influences on the status of women in nursing in 
Saudi Arabia. Online J Issues Nurs 2006;11(3):8. PMid:17279862

23. Barbarà-i-Molinero A, Cascón-Pereira R, Hernández-Lara AB. Professional identity development in higher education: Influencing factors. Int J Educ Manag. 2017;31(2):189-203. https://doi.org/10.1108/ijem-05-2015-0058

24. Pimenta $A D$, Souza MD. The Professional Identity of Nursing in the Papers Published by Reben. Vol. 26. Texto and Contexto-Enfermagem; 2017. https://doi. org/10.1590/0104-07072016004370015

25. Vaismoradi M, Salsali M, Ahmadi F. Perspectives of Iranian male nursing students regarding the role of nursing education in developing a professional identity: A content analysis study. Jpn J Nurs Sci. 2011;8(2):174-83. https://doi. org/10.1111/j.1742-7924.2010.00172.x PMid:22117581

26. Fitzgerald AM. The Experience of Professional Identity Development in Graduating Nursing Students; 2016.

27. Keith JM. Florence nightingale: Statistician and consultant epidemiologist. Int Nurs Rev 1988;35(5):147-50. PMid:3053483

28. Hoyt S. Florence Nightingale's contribution to contemporary nursing ethics. J Holist Nurs. 2010;28(4):331-2. https://doi. org/10.1177/0898010110383281 PMid:21149560

29. Jan R. Rufaida Al-Asalmiya, the first muslim nurse. Image J Nurs Sch. 1996;28(3):267-8. https://doi. org/10.1111/j.1547-5069.1996.tb00362.x PMid:8854550

30. Ismail S, Hatthakit U, Chinnawong T. Islamic Based Caring in Nursing Science: A Literature Review. Paper Presented at the ASEAN/Asian Academic Society International Conference Proceeding Series; 2015.

31. Asosiasi Institusi Pendidikan Ners Indonesia. Kurikulum Inti Pendidikan Ners 2015. Jakarta: Asosiasi Institusi Pendidikan Ners Indonesia; 2016. https://doi.org/10.35974/jsk.v2i2.559

32. Abdullah $\mathrm{KL}$, Chong MC. Factors influencing professional values among Indonesian undergraduate nursing students. Nurse Educ Pract. 2019;41:102648. https://doi.org/10.1016/j. nepr.2019.102648

PMid:31707147

33. Maxwell JA. Applied Social Research Methods Series: Qualitative Research Design: An Interactive Approach. Vol. 41. Thousand Oaks: Sage; 2013.

34. Sandelowski M. What's in a name? Qualitative description revisited. Res Nurs Health. 2010;33(1):77-84. https://doi. org/10.1002/nur.20362 PMid:20014004

35. Spouse J. Talking pictures: Investigating personal knowledge through illuminative art-work. NT Res. 2000;5(4):253-61. https:// doi.org/10.1177/136140960000500404

36. Colaizzi PF. Psychological research as a phenomenologist views it. In: Valle RS, King M, editors. Existential-Phenomenological Alternatives for Psychology. New York: Oxford University Press; 1978. p. 48-71.

37. Morrow R, Rodriguez A, King N. Colaizzi's descriptive phenomenological method. Psychologist 2015;28(8):643-4.

38. Carnevale FA. Authentic qualitative research and the quest for methodological rigour. Can J Nurs Res Arch. 2016;34(2):121-8. PMid:12425004

39. Guillemin M. Understanding illness: Using drawings as a research method. Qual Health Res. 2004;14(2):272-89. https:// doi.org/10.1177/1049732303260445

\section{PMid: 14768462}

40. LRI. Law of the Republic of Indonesia No. 34 year 2014 on Nursing Act: President of the Republic of Indonesia; 2014.

41. Saeed A. Islamic Thought: An Introduction. Milton Park: Routledge; 2006.

42. Charles CE, Daroszewski EB. Culturally competent nursing care of the Muslim patient. Issues Ment Health Nurs. 2011;33(1):613. https://doi.org/10.3109/01612840.2011.596613 PMid:22224968

43. Shafakhah M, Molazem Z, Khademi M, Sharif F. Facilitators and inhibitors in developing professional values in nursing students. Nurs Ethics. 2018;25(2):153-64. https://doi. org/10.1177/0969733016664981

\section{PMid:27664036}

44. Almukhaini SJ, Goldberg L, Watson J. Embodying caring science as islamic philosophy of care: Implications for nursing practice. Adv Nurs Sci. 2020;43(1):62-74. https://doi.org/10.1097/ ans. 0000000000000300 PMid:31922984

45. Rassool GH. The crescent and Islam: healing, nursing and the spiritual dimension. Some considerations towards an understanding of the Islamic perspectives on caring. J Adv Nurs. 2000;32(6):1476-84. https://doi. org/10.1046/j.1365-2648.2000.01614.x

PMid:11136416

46. Leininger $M$. Quality of life from a transcultural nursing perspective. Nurs Sci Q. 1994;7(1):22-8.

PMid:8139812

47. Watson J. In: Boulder CO, editor. Nursing: The Philosophy and Science of Caring. Boulder: University Press of Colorado; 2008.

48. Atkinson $C$. Islamic values and nursing practice in Kuwait. J Holist Nurs. 2015;33(3):195-204. https://doi. org/10.1177/0898010114564682

PMid:25575602

49. Noviani W. Perception of Ners Profession Students on Indonesian Nurses Ethic Codes in Teaching Hospitals of Universitas Muhammadiyah Yogyakarta. Indones J Nurs Pract. 2016;1(1):30-9. https://doi.org/10.18196/ijnp.1148

50. Zahedi $F$, Sanjari M, Aala M, Peymani M, Aramesh K, Parsapour A, et al. The code of ethics for nurses. Iran J Public Health. 2013;42(Supple1):1-8 PMid:23865008

51. Parandavar N, Rahmanian A, Jahromi ZB. A study of the relationship between nurses' professional self-concept and professional ethics in hospitals affiliated to Jahrom University of Medical Sciences, Iran. Glob J Health Sci. 2016;8(4):82-8. https://doi.org/10.5539/gjhs.v8n4p82

PMid:26573035

52. Ross L, Van Leeuwen R, Baldacchino D, Giske T, McSherry W, Narayanasamy A, et al. Student nurses perceptions of spirituality and competence in delivering spiritual care: A European pilot study. Nurse Educ Today. 2014;34(5):697-702. https://doi. org/10.1016/j.nedt.2013.09.014

PMid:24119953

53. Neishabouri M, Ahmadi F, Kazemnejad A. Iranian nursing students' perspectives on transition to professional identity: A qualitative study. Int Nurs Rev. 2017;64(3):428-36. https://doi. org/10.1111/inr.12334

PMid:27882563

54. Takase S, Tsuchiya R, Nishizawa $Y$. The influence of personal characteristics and learning motivation on the professional identity of nursing students. Hirosaki Med J. 2019;69(1-4):66-77. 